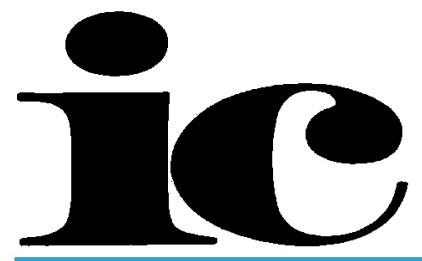

INEDCTION

CXNTTROL.

\title{
Hospital Infection Control - An International Perspective
}

During the last decade, recognition of the problem of hospital-acquired infections has increased dramatically in industrialized countries. Subsequent measures to control and prevent these infections have demonstrated both the necessity and effectiveness of hospital infection control (HIC) programs. Incidence of infection has decreased with major economic savings. In the United States, national HIC guidelines were developed, and infection control committees were made mandatory for certification by the American Hospital Association. Assuming an initial hospital acquired infection rate of $5 \%$ in the United States, the Centers for Disease Control has estimated that $20 \%$ of hospital-acquired infections are being prevented with an estimated total savings each year of $\$ 277,106,000$. The estimated total cost of the HIC program in the United States is $\$ 71,840,000$. $^{1}$

As developing countries adopt and adapt modern medical technologies in existing and newly constructed hospitals, HIC programs will become essential to maintain a positive health impact and justify the expenditures. In the World Health Organization's (WHO) Region of the Americas (Western Hemisphere), there is growing concern for hospital-acquired infections. Canada and the United States, however, are the only countries that have fully implemented national HIC programs.

How serious is the problem in other western countries? Anecdotes can provide some insight in spite of their obvious biases and limitations. In one capital city in the teaching hospital of the national medical school, three separate outbreaks of diarrheal disease occurred in the premature nursery during the past year. The average census of the nursery was 12 to 15 infants. In each instance, the attack rate was $100 \%$, (all the children became infected)

Address reprint requests to Ronald K. St. John, M.D., Chief, Communicable Diseases, Division of Disease Prevention and Control, Pan American Health Organization, Regional Office of the Americas, Washington, D.C. 20037. and the mortality rate was $100 \%$ (all the children died). The pathological agent was never identified and no epidemiological investigation was undertaken to identify the probable source(s) of the outbreaks.

At the only pediatric hospital in one Central American country, the occurrence of diarrheal disease in children frequently exceeds $100 \%$ during hospitalization. In other words, if a child did not suffer from diarrhea on admission, it was virtually certain he would acquire an enteric infection before death or discharge. Multiple episodes are common, especially in high-risk, malnourished children. In this same country, diarrheal disease prevalence rates among adult patients of $20 \%$ to $30 \%$ are considered common and no cause for alarm.

In another capital city in a major children's hospital with over 600 beds and 8,200 discharges per year, disposable scalp vein "butterfly" needles are inserted and left in place until they clot or infiltrate. Then they are withdrawn, flushed, wiped with an alcohol soaked cotton swab and reinserted into another site. This disposable needle is often "sterilized" and re-used in another patient. In this hospital, frequent outbreaks of multiple drug resistant Klebsiella septicemia occur.

To determine how representative these impressions are, we conducted a five-year Medlars review of published articles on hospital-acquired infections originating from developing and/or tropical countries. Of the 53 citations, the majority came from India (11), Brazil (9), Mexico (6), Chile (5), Nigeria (3), Panama (2), and Zimbabwe (2). Overall infection rates varied from $3 \%$ to $12 \%$ with higher figures from surgical $(7.1 \%$ to $68 \%$ ), pediatric $(3.6 \%$ to $16.7 \%)$, intensive care $(11.3 \%$ to $24.1 \%)$, and burn units (7.8\% to $35.4 \%)$. The majority of epidemic investigations involve diarrhea disease outbreaks in premature nurseries and on pediatric wards.

There are very few published reports of hospital surveillance data and the information is contradictory. The report by Kimberlin and Hariri ${ }^{2}$ from an Iranian 


\section{TABLE}

\section{PREVALENCE RATES}

OCTOBER TO DECEMBER 1982

\begin{tabular}{lrrrr} 
Service & October & November & December & Overall \\
\hline $\begin{array}{l}\text { Orthopedics/ } \\
\text { Trauma }\end{array}$ & $30 \%$ & $18 \%$ & $8 \%$ & $20 \%$ \\
Urology & $23 \%$ & $7 \%$ & $5 \%$ & $12 \%$ \\
\hline
\end{tabular}

hospital is particularly instructive. From 1976 to 1978 the institution experienced five distinct major outbreaks of nosocomial infections with attack rates on involved services from $50 \%$ to $87.5 \%$. The Hospital das Clinicas, a leading hospital in Sao Paulo, has published a series of articles summarizing its experiences from 1971 to 1972 , 1974 , and $1975 .{ }^{3-5}$ While the overall infection rate was $6 \%$ from 1971 to 1972 , it had risen to $11.2 \%$ and $12 \%$ from 1974 to 1975 . By contrast, wound infections at University College Hospital in Ibadan, Nigeria fell from $27 \%$ in 1970 to an overall rate of $10.2 \%$ in $1976 .{ }^{6}$ It is difficult to determine from the articles how greatly differences in methodology, the introduction of surveillance and the institution of control measures contributed to these striking changes.

Available data from many areas of Latin America are equally difficult to evaluate. Recent unpublished studies supported by the Pan American Health Organization (PAHO), the WHO's Regional Office of the Americas, have shown prevalence rates ranging from $5 \%$ to $70 \%$. In a major hospital in Ecuador rates were obtained during special prevalence studies in October, November, and December, 1980 (Table). ${ }^{7}$ Of major interest is the dramatic decline in rates during the study period. Once surveillance was initiated, there was a significant increase in awareness of the problem and hospital personnel resurrected existing guidelines and instituted new practices for infection control.

Costa Rica and Panama have accumulated some information from pioneer HIC programs that were started in the late 1970s. In Costa Rica overall post-surgical infection rates in 1981 (January through July) were $6 \%$ to $8 \%$ while overall hospital infection rates were recorded as $1 \%$ to $4 \%{ }^{8}$ In one hospital complex in Panama overall hospital infection incidence rates were $2 \%$ to $3 \%$ with rates on the medical and surgical services ranging from $1 \%$ to $4 \%$ and $4 \%$ to $6 \%$ respectively.

The institutions that are beginning to organize HIC programs and publish their data are the current leaders in HIC and, generally speaking, are the more sophisticated teaching hospitals. As such, their experience is not necessarily typical or representative.

Since the mid-1970s, the PAHO has promoted HIC activities among member countries as part of the Ten Year Health Plan for the Americas (1970). Early efforts focused on Central American countries because of interest expressed by the Ministries of Health. Initial progress resulted from the efforts of a PAHO nurse epidemiologist assigned to the PAHO Area Office in Guatemala in 1977. Infection control committees were organized or strengthened in major cities of Colombia, Ecuador, El Salvador, Costa Rica, Guatemala, Panama and Venezuela. In response to requests by the PAHO Advisory Committee on Medical Research (ACMR) PAHO organized a major multidisciplinary conference in 1979 in Guatemala for Latin America to determine the state of control programs and develop strategies for their approval and participation.* The conference report identified the nine essential elements of HIC, specifically, the establishment of a functioning infection control committee; an operational surveillance system; patient isolation facilities and procedures; a functioning employee health program; guidelines for aseptic techniques and use of antibiotics; minimal microbiological laboratory support; professional, ongoing education programs for hospital personnel; guidelines and procedures for general housekeeping, and established liaison between the hospital and all other community health services and facilities. The Conference also outlined approaches and strategies for HIC and recommended specific training and operational research programs. In support of initial efforts, PAHO will reemphasize and expand its HIC efforts to include attempts to increase awareness of the problem through motivational seminars and symposia and opportunities for specific training through special HIC workshops, courses and fellowships.

Nations in the Americas are utilizing old existing hospitals and building new, ultra-modern facilities. High-level medical technology is imported and utilized. As the level of sophistication increases, there will be an increasing need to implement effective HIC programs. Without them, new modern hospitals with their dialysis units, intensive care wards, premature nurseries, blood and blood products banks and sophisticated diagnostic laboratories will be counterproductive. Hospital infections and their associated costs negate the health benefits of modern patient care technology.

In most countries there is increasing interest and concern. In some (Chile, Colombia, Costa Rica, Ecuador, Mexico, Panama), there are pilot or demonstration HIC programs in some of the hospitals of the capital city. There is a tendency in some programs to rely on environmental sampling or information obtained from agents isolated in the bacteriology laboratory. Surveillance is often carried out alone without adequate control measures or concern for other elements of a complete program. These approaches may prove to be neither cost effective nor economically feasible in developing countries.

Patient-based surveillance that utilizes open-minded, flexible approaches in response to local needs and problems is needed for successful HIC programs. The nurse-epidemiologist model which has been successfully used in the United States may not be the most effective approach in all cultures and health care systems.

*The report of this conference is available in English or Spanish from PAHO 525, 23rd Street, N.W., Washington, D.C. 20037. 
Professional relationships and physician, nurse, laboratory and auxiliary health personnel ratios must be considered in selecting the professional responsible for epidemiological activities and the administration of the overall programs. What is clear, however, is that any of the above health professionals can implement an effective program when proper training is provided.

In the developing countries, much remains to be learned about the incidence and epidemiology of hospital infections.

Unlike industrialized countries, infectious diseases such as Salmonella, shigella, enteric viruses, measles and other vaccine preventable diseases, and tuberculosis still cause considerable death and disease. Community-acquired infections, therefore, are more likely to cause problems in health care institutions. Will hospital infections be similar in all institutions or will there be urban vs. rural, affluent vs. poor or general vs. specialized differences? If so, what are the risk factors contributing to these differences?

The role of cultural practices within the hospital ecology must also be defined. Does it matter that wards are open, crowded, and easily accessible to the patient's extended family and friends? How important is handwashing and what measures can be adopted in hospitals with limited, unpredictable, non-potable water supplies? How important are toilet facilities for patients and staff? Is it important if family and friends bring food purchased from outside vendors into the hospital environment? Does air conditioning reduce or increase the risk for patients? The role of traditional HIC practices that are widely accepted in developed countries (sometimes with little supporting data) should be reevaluated. Infection rates should be carefully defined and HIC control measures evaluated in different settings. Professionals involved in HIC in industrialized countries stand to learn much from their colleagues in developing countries.

HIC programs in developing countries must make do with limited resources and funds. These countries will be looking for simplified approaches at the lowest possible cost. Of necessity they will opt for the best cost/benefit ratios and these must be identified and evaluated as soon as possible.

\section{REFERENCES}

1. Haley RW: Preliminary cost/benefit analysis of hospital infection control programs (The SENIC Project), in Daschner F (ed):
Proceedings of an International Workshop, Baiersbrown, West Germany, September 24-25, 1977. New York, Gustav Fischer Verlag, 1978.

2. Kimberlin CL, Hariri AR: Nosocomial infections - Problems in a developing country. $R$ Soc Health $J$ 1981, 101(2):74-77.

3. Hutzler RU, Stape DDB, Ulson DM, et al: Uso de antimicrobianose infeccoes em Hospitais Universitarios. Revista Paulista de Medicina 1974; 83:250-258.

4. de Vasconcelos RF, Stape DDB, Hutzler RU, et al: Prevalencia de doentes infectados e uso de antimicrobianos em Hospital Universitario - 1974. Revista do Hospital das Clinicas 1976; 31:208-214.

5. Rodriguez E, Hutzler RU, de Vasconcelos RF, et al: Prevalencia de doentes infectados e uso de antimicrobianos em Hospital Universitario - 1975. Revista do Hospital das Clinicas 1977; 22:289-295.

6. Montefiore D: Epidemiological surveillance of hospital-acquired wound infections - A report from the control of infection subcommittee University College Hospital, Ibadan. Nigerian Medical Journal 1979; 9:289-293.

7. Castro JY: Estudio de Infecciones Intrahospitalarias en Pacientes Hospitalizados en los Servicios de Urologia, Ortopedia y Traumatologia del Hospital Carlos Andrade Marin, Durante los Meses de Octubre, Noviembre, Diciembre, 1980. Instituto Ecuatoriano de Seguridad Social, unpublished data.

8. Infection Control Committee: Comite Infecciones Intrahospitalarias, Caja Costarricense de Seguro Social. San Jose, Costa Rica, Hospital Mexico, unpublished data.

9. Infection Control Committee: Comite de Infecciones, Caja de Seguro Social. Panama, Metropolitan Hospital Complex, unpublished data.

\section{ACKNOWLEDGMENT}

The authors wish to express their gratitude to Ms. Marti Messerli, Johns Hopkins School of Hygiene and Public Health, for her invaluable assistance in the preparation of this editorial.

KARL A. WESTERN, M.D. Assistant Director for International Research National Institute of Allergy and Infectious Diseases National Institutes of Health Bethesda, Maryland

RONALD K. ST. JOHN, M.D. Chief, Communicable Diseases Division of Disease Prevention and Control Pan American Health Organization Washington, D.C.

LOIS ANN SHEARER Infectious Disease Section California State Department of Health Berkeley, California 